\title{
Insights from social sciences can help build an eco-surplus culture for conservation policymaking
}

\author{
Minh-Hoang Nguyen \\ Ritsumeikan Asia Pacific University \\ Beppu, Oita 874-8577, Japan \\ January 03, 2022

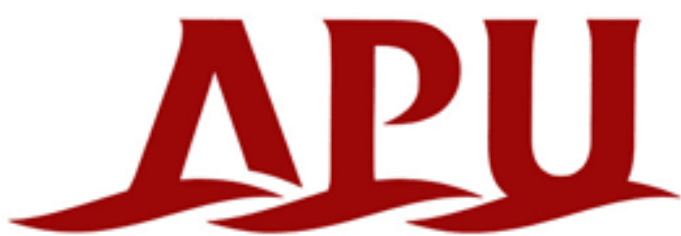 \\ Ritsumeikan Asia Pacific University \\ $* * * * *$
}

For several decades, scientific and technological innovations have been expected to be key solutions for many global problems, including environmental degradation [1]. However, we cannot ignore the fact that humans play a vital role in the Earth ecological systems, and many environmental problems are mainly caused by anthropogenic activities, such as biodiversity loss. Thus, proper policymaking to improve biodiversity conservation and curb biodiversity must include humanities and social sciences insights. This viewpoint shares the same sentiment with author Hetan Shah's saying [2]:

"In diverse cases, social factors - cultural norms, educational understanding, kin and social networks, power dynamics, or simply the layout of a building - must be accounted for before policy can succeed. Blind faith in data science without an understanding of what data are missing, or how algorithms can exacerbate existing biases, can lead to policy failure."

Efforts to advocate the importance of insights from human dimensions in conservation policymaking and actions are growing. The emergence of the new research field in conservation sciences - conservation social sciences - is a typical example [3].

In line with conservation social scientists, I contend that understanding how people adapt and change their attitudes and behaviors towards biodiversity concepts is crucial for tackling biodiversity loss through building an eco-surplus culture in urban areas $[4,5]$. Eco-surplus culture is a set of pro-environmental norms, practices, and values to reduce negative anthropogenic impacts on environments and conserve and restore nature [6]. My argument can be defended by various studies that have confirmed the positive 
relationships between interactions with nature and attitudes towards biodiversity [7-9] and the biophilia hypothesis $[10,11]$.

\section{References}

1. Vuong QH. (2021). Western monopoly of climate science is creating an eco-deficit culture. Economy, Land \& Climate Insight. Retrieved from: https://elcinsight.org/western-monopoly-of-climate-science-is-creating-an-eco-deficitculture/

2. Shah H. (2020). Global problems need social science. Nature, 577, 295.

3. Bennett NJ. Et al. (2017). Conservation social science: Understanding and integrating human dimensions to improve conservation. Biological Conservation, 205, 93-108.

4. Nguyen MH, Jones TE. (2021). Predictors of support for biodiversity loss countermeasures and bushmeat consumption among Vietnamese urban residents. OSF Preprints. Retrieved from: https://osf.io/9kdbw/

5. Nguyen MH. (2021). Building an eco-surplus culture is a possible solution for curbing environmental problems. OSF Preprints. Retrieved from: https://osf.io/qa9dx/

6. Vuong $\mathrm{QH}$. (2021). The semiconducting principle of monetary and environmental values exchange. Economics and Business Letters, 9 (3), 284-290.

7. Zhang W, Goodale E, Chen J. (2014). How contact with nature affects children's biophilia, biophobia and conservation attitude in China. Biological Conservation, 177, 109-116.

8. Soga M, et al. (2016). Both Direct and Vicarious Experiences of Nature Affect Children's Willingness to Conserve Biodiversity. International Journal of Environmental Research and Public Health, 13 (6), 529.

9. Hosaka T, Sugimoto K, Numata S. (2017). Childhood experience of nature influences the willingness to coexist with biodiversity in cities. Palgrave Communications, 3, 17071.

10. Kellert SR, Wilson EO. (1993). The Biophilia Hypothesis. Island Press: Washington, D. C.

11. Simaika JP, Samways MJ. (2010). Biophilia as a universal ethic for conserving biodiversity. Conservation Biology, 24 (3), 903-906. 